\title{
Exploratory factor analysis of a score for grading the severity of bronchial obstruction evaluated in children younger than 3 years old, Chile, 2015
}

\author{
Soledad Luarte-Martínez, Physical Therapist and Magister, ${ }^{a, b, f}$ and \\ Paula Astudillo Díaz, Nurse and Magister. ${ }^{b, c, d, e}$
}

\begin{abstract}
a. Department of
Kinesiology,

Universidad

de Concepción,

Concepción, Chile.

b. Doctoral Program

in Medical Sciences,

Universidad de la

Frontera, Chile.

c. Department

of Surgery,

Traumatology, and

Anesthesiology of

Universidad de La

Frontera, Chile.

d.Doctoral Program

in Medical Sciences,

Universidad de la

Frontera, Chile.

e. Doctoral Program in

Psychology, Health, and Quality of Life,

Universidad de

Girona, Spain.

f. Research Task Force in Cardiovascular and Respiratory Health IDEAS-CVR, Concepción, Chile.
\end{abstract}

E-mail address:

Paula Astudillo Díaz, Nurse and Magister: paula.astudillo@ ufrontera.cl

Funding:

This study was

funded by the Vice-

Rectorship of Research

and Development

(Vicerrectoría de

Investigación y

Desarrollo, VRID)

of Universidad de

Concepción, project no.

215.082.050IN.

Conflict of interest:

None.

Received: 12-13-2016

Accepted: 7-3-2017

\begin{abstract}
Introduction. The modified Tal's score has been used in Chile to determine the severity of bronchial obstruction. Its validity has been reported already; however, its structure as a scale to significantly quantify the severity of bronchial obstruction has not been analyzed.

Objective. To identify the relationship pattern among the score's items and the severity of bronchial obstruction in a sample of children younger than 3 years seen in two health care centers in the province of Concepción, Chile.

Method. Exploratory factor analysis. Nonrandom, voluntary selection of participants youngerthan36months, August-November 2015. Participants were assessed independently and subsequently by a physician and a physical therapist. The following measurements were applied: central tendency, exploratory factor analysis, subgroups of participants younger and older than 6 months, and internal consistency. Results. A total of 204 measurements were done in 102 children. With a $39 \%$ explained variance, items incline towards to two different concepts: one factor groups respiratory rate, wheezing, and retractions, and the other determines only cyanosis, with a Cronbach's alpha of 0.5 . Once cyanosis is removed from the analysis, the original one-factor matrix sample shows a $38 \%$ total explained variance and a 0.62 internal consistency.

Conclusions. Based on its items, the score's structure does not fit adequately to this sample. Cyanosis appears as a dissociated item within the structure. Once the model is adjusted to only 3 items, the stability of Chronbach's alpha as a measure of internal consistency increases but at an objectionable value, which will undoubtedly vary once it is applied to a different sample. Key words: exploratory factor analysis, obstructive pulmonary diseases, scales.
\end{abstract}

http:/ / dx.doi.org/10.5546/ aap.2017.eng.e370

To cite: Luarte-Martínez S, Astudillo Díaz P. Exploratory factor analysis of a score for grading the severity of bronchial obstruction evaluated in children younger than 3 years old, Chile, 2015. Arch Argent Pediatr 2017;115(6):e370-e376.

\section{INTRODUCTION}

In Latin America, acute respiratory infections (ARIs) have been the main reason for consultation in primary care settings. ${ }^{1}$ ARIs account for the highest percentage of annual visits; in average, 56\% correspond to acute upper respiratory infections and $44 \%$, to acute lower respiratory infections, making them the main reason for hospitalization in pediatrics. ${ }^{1-3}$

In Chile, in 1994, pneumonia was the main cause of late infant mortality. ${ }^{2,3}$ The National Ministry of Health of Chile (MoH) launched a strategy that included a unified ARI program to establish the priority of care based on clinical parameters, which helped to reduce the number of infant deaths from 16 per 1000 live births in 1990 to 7.9 per 1000 live births in 2009.,

In this context, several clinical scores have been developed to determine the severity of bronchial obstruction (SBO). ${ }^{5,6}$ One of these is the modified Tal's score, developed by Bierman and Pearson in $1974 .{ }^{7}$ In $1983,{ }^{8}$ it was modified by Tal, who replaced the inspiratory-expiratory ratio by the presence of cyanosis. Later, in Chile, ${ }^{4}$ differentiations by age were included, and the $\mathrm{MoH}$ recommended its use in its Guideline for Respiratory Infections.

Tal's score was validated by Pavón ${ }^{9}$ and showed an adequate correlation with oxygen saturation $\left(\mathrm{SaO}_{2}\right)(\mathrm{r}=-0.76,95 \%$ confidence interval [CI]: -0.83 to -0.68 ).

In 2007, Coarasa ${ }^{10}$ assessed the ability to predict $\mathrm{SaO}_{2}$ below or equal to 91 and showed a sensitivity lower than its Argentine counterpart, and a higher specificity (56\% versus $100 \%$ 
and $92.6 \%$ versus $54.3 \%$, respectively; $p<0.001$ ). Puebla ${ }^{11}$ assessed its diagnostic use by nonmedical health care professionals and found a $77 \%$ sensitivity (95\% CI: 70-82\%) and an $88.4 \%$ specificity (95\% CI: 84-92\%). McCallum ${ }^{12}$ assessed the internal consistency (IC) and reliability of Tal's score and modified Tal's score and indicated that both scores showed an adequate internal consistency (a Cronbach's alpha of 0.66 and 0.7, respectively) and an adequate inter-observer reliability, Kappa index: 0.72 (95\% CI: 0.63, 0.76) and 0.70 (95\% CI: $0.63,0.83)$, respectively.

Although there was evidence of the modified Tal's score performance as a predictor of hypoxemia, it is necessary to assess other validity elements, ${ }^{13-15}$ such as the assessment of its structure as score by means of its items to confirm the representativeness of the studied phenomenon. This is an unusual analysis in the health care setting but it is relevant to establish validity given that the Chilean's $\mathrm{MoH}$ uses it as a model of measure ${ }^{3,16}$ that should summarize the SBO precisely.

Objective: To identify the relationship pattern among the score's items and the SBO in a sample of children younger than 3 years seen in two health care centers in the province of Concepción, Chile.

\section{METHODOLOGY}

Design: An exploratory factor analysis (EFA) is a statistical model that represents the relationships among a set of outcome measures. Such approximation will explore the relationship patterns between the latent outcome measure (SBO) and evident outcome measures (items), identify the number and composition of necessary outcome measures to explain common variance of the sets of items analyzed. Inductive approximation searches for relationship patterns among indicators (items) and defines the construct (SBO). Such procedure for exploratory perspective may have significant implications on theoretical model inferences, ${ }^{17}$ because it works based on empirical measurements of indicators towards the construct definition. It makes references to an instrument's ability to quantify, in a significant and adequate manner, the feature for whose measurement has been designed.

\section{Design assumptions}

- Each observed outcome measure or item was selected to reflect the characteristic of the factor to be measured, in this case, the SBO.
- People with different levels in the common factor (SBO) will respond differently to this item, precisely because the factor causes different responses to this item (the item is a manifestation of the SBO).

Subjects: The sample size was based on Streiner's recommendations, ${ }^{18}$ who proposed a minimum of 10 observations by item in the score to be validated. A minimum of 40 observations was estimated.

Participants were selected in a non-random and voluntary manner (guardians). Participants were pediatric patients attending their first visit to Centro de Salud Víctor Manuel Fernández and Hospital Guillermo Grant Benavente, in the province of Concepción, between August and November 2015. Inclusion criteria: children younger than 36 months with obstructive bronchial disease (diagnosed by the resident physician). Children with chronic pulmonary disease previously diagnosed were excluded.

Data collection: Two independent observers, a physician and a physical therapist (health care center), assessed patients subsequently (to avoid any variations in clinical signs) and assigned a score to each item and the total score. A pre-test was done to determine the necessary time and any inconvenience in the subsequent assessments. The database was managed using Access ${ }^{\circledR}$ software.

\section{Score outcome measures}

- Biodemographic outcome measures: sex, age (months old), maternal education (highest completed level), number of household members, attendance to a day care centerkindergarten (yes/no). Data were collected during an interview with the observer.

- One-factor, 4-item score: respiratory rate, wheezing, cyanosis, retractions. A Likert-type scale was used, where " 0 " meant absence of manifestations or normal manifestations, and “3", a high-risk manifestation:

- Respiratory rate, sub-divided into participants younger than 6 months ( $\leq 40$ breaths per minute $[\mathrm{bpm}], 41-55 \mathrm{bpm}, 56-70 \mathrm{bpm}$, $>70 \mathrm{bpm}$ ) and aged 6 months or older ( $\leq 30 \mathrm{bpm}, 31-45 \mathrm{bpm}, 46-60 \mathrm{bpm},>60 \mathrm{bpm}$ ).

- Wheezing (audible from a distance, inspiration and expiration with phonendoscope, end of expiration with phonendoscope, absence).

- Cyanosis (generalized, peri-oral at rest, perioral during crying, absence).

- Retractions (supraclavicular, intercostal, subcostal, absence). 


\section{Analysis plan}

Relationship patterns were searched for in terms of variance. The item's predictive ability was not analyzed, but if such item was effectively related in terms of characterizing the SBO.

Central tendency measures and frequency distribution were investigated. Out-of-range data were extracted for the EFA. This served as a quality control before the analysis, called "outliers." Atypical values could have a disproportionate effect in statistical results, which could lead to misleading interpretations.

To assess the relevance of the EFA, the alleged correlation among outcome measures was analyzed. To establish whether its application was or not justified, correlations between each item in the score were looked for using Spearman's

TABLE 1. Sociodemographic outcome measures $(n=102)$

\begin{tabular}{ll}
\hline Outcome measure & $\%$ \\
\hline Maternal education & \\
$\quad$ Primary & 14.7 \\
$\quad$ Secondary & 59.8 \\
$\quad$ Tertiary & 25.5 \\
No. of people sharing the household & \\
$\quad \geq 5$ & 32.4 \\
$\quad<5$ & 67.7 \\
Attending a day care center & \\
$\quad$ Yes & 33.3 \\
$\quad$ No & 66.7 \\
\hline
\end{tabular}

Rho correlation; Kaiser-Meyer-Olkin measure of sampling adequacy (KMO) and Bartlett's sphericity test were applied, and sampling adequacy was considered adequate if values were above 0.6.

Later, conceiving the error, a method for the extraction of main axes and varimax rotation were used to reach the factor matrix, followed by the analysis of IC with Cronbach's alpha; the work was conducted based on George and Mallery's recommendations: $:^{19}$ above 0.7 , acceptable; higher than 0.6 , objectionable; and higher than 0.5 , poor. The SPSS $11^{\circledR}$ software was used.

Matrices were analyzed for $\leq 6$ months old and $>6$ months old.

\section{Ethical aspects of research}

Patient's legal guardians participated voluntarily once they signed the consent. The study was approved (code CEC:15-07-40) by the Ethics Committee of the Health Department of Concepción, Chile, in August 2015.

\section{RESULTS}

\section{Descriptive analysis}

A total of 204 assesments of the score were done in 102 pediatric patients: 42 girls (41.2\%) and 60 boys (58.8\%). The patient's median age was 10 months (1-35 months); $67.7 \%$ shared the household with less than 5 other people; $66.7 \%$ did not regularly attend a day care center, so they

TABLE 2. Description by frequency of the score's outcome measures and differences in proportions by observer

\begin{tabular}{|c|c|c|c|c|}
\hline Outcome measure & Category & hysician $(n=102)$ & Physical therapist $(n=102)$ & $P$ value \\
\hline $\mathrm{RR} \leq 6$ months old & $\begin{array}{l}\leq 40 \mathrm{bpm} \\
41-55 \mathrm{bpm} \\
56-70 \mathrm{bpm} \\
>70 \mathrm{bpm}\end{array}$ & $\begin{array}{c}1 \\
18 \\
87 \\
1\end{array}$ & $\begin{array}{c}8 \\
12 \\
13 \\
1\end{array}$ & 0.5925 \\
\hline RR $>6$ months old & $\begin{array}{l}\leq 30 \mathrm{bpm} \\
31-45 \mathrm{bpm} \\
45-60 \mathrm{bpm} \\
>60 \mathrm{bpm}\end{array}$ & $\begin{array}{c}23 \\
38 \\
13 \\
4\end{array}$ & $\begin{array}{c}24 \\
36 \\
15 \\
3\end{array}$ & 0.4 \\
\hline $\begin{array}{r}\text { Wheezing } \\
\text { Inspira }\end{array}$ & $\begin{array}{l}\text { Absence } \\
\mathrm{f} \text { expiration } \mathrm{w} / \mathrm{phonendoscope} \\
\mathrm{n} \text { and expiration } \mathrm{w} / \text { phonendoscope } \\
\text { Audible from a distance }\end{array}$ & $\begin{array}{c}34 \\
51 \\
12 \\
5\end{array}$ & $\begin{array}{c}30 \\
53 \\
13 \\
6\end{array}$ & 0.4698 \\
\hline Cyanosis & $\begin{array}{c}\text { Absence } \\
\text { Peri-oral during crying } \\
\text { Peri-oral at rest } \\
\text { Generalized at rest }\end{array}$ & $\begin{array}{c}100 \\
2 \\
0 \\
0\end{array}$ & $\begin{array}{c}102 \\
0 \\
0 \\
0\end{array}$ & 0.0001 \\
\hline Retractions & $\begin{array}{c}\text { Absence } \\
\text { Subcostal }(+) \\
\text { Intercostal }(++) \\
\text { Supraclavicular }(+++)\end{array}$ & $\begin{array}{l}41 \\
41 \\
14 \\
5\end{array}$ & $\begin{array}{c}45 \\
41 \\
12 \\
4\end{array}$ & 0.0049 \\
\hline
\end{tabular}

RR: respiratory rate. 
were looked after by their parents or caregivers; $85.3 \%$ of mothers had completed secondary or tertiary education (Table 1).

In the frequency distribution of outcome measures of the modified Tal's score and in the differences in proportions by observer, the $p$ value for cyanosis showed that there could be differences; however, these could be related to the absence of a larger number of severe cases collected (Table 2).

In relation to the total score observed in participants older and younger than 6 months, the SBO was mild (Table 3).

\section{Exploratory factor analysis}

Out-of-range values were estimated by computing the range, standard deviation, individual average, coefficient of variation using the Mahalanobis distance; 179 measurements were obtained. The EFA was done based on these 179 measurements.

The EFA was started by estimating Spearman's Rho correlations (Table 4).

The factor matrix, with a $39 \%$ explained variance, showed two factors; one grouped respiratory rate, wheezing, and retractions, the other, cyanosis. With low correlations, and fixing only one factor, the item "cyanosis" was dissociated from the rest of the items and failed to explain the SBO construct. An IC of 0.5 was calculated (Table 5).

Based on the results, a new matrix was

TABLE 3. Modified Tal's score

\begin{tabular}{lcc}
\hline Outcome measure & $\begin{array}{c}\mathbf{6} \text { months old } \\
(\mathbf{n}=\mathbf{2 6})\end{array}$ & $\begin{array}{c}>\mathbf{6} \text { months old } \\
(\mathbf{n}=\mathbf{7 6})\end{array}$ \\
\hline Respiratory rate & $1(0-2)$ & $1(0-3)$ \\
Wheezing & $1(0-2)$ & $1(0-3)$ \\
Cyanosis & $0(0-0)$ & $0(0-1)$ \\
Retractions & $1(0-2)$ & $1(0-3)$ \\
Total score & $3(0-6)$ & $3(0-9)$ \\
\hline
\end{tabular}

Results are expressed as median and range.

TABLE 4. Spearman's correlation among each item in the score ( $n=179$ measurements)

\begin{tabular}{lcccc}
\hline & $\begin{array}{c}\text { Respiratory } \\
\text { rate }\end{array}$ & Wheezing Cyanosis & Retractions \\
\hline $\begin{array}{l}\text { Respiratory } \\
\text { rate }\end{array}$ & 1 & 0.23 & -0.17 & 0.47 \\
Wheezing & 0.23 & 1 & -0.79 & 0.24 \\
Cyanosis & -0.17 & -0.79 & 1 & 0.10 \\
Retractions & 0.47 & 0.24 & 0.01 & 1 \\
\hline
\end{tabular}

developed excluding cyanosis from analysis, and a one-factor matrix (which accounted for the SBO construct) and the items "respiratory rate," "wheezing" and "retractions" were obtained, with $38 \%$ of total variance. Factor loads for respiratory rate, wheezing, and retractions were $0.64,0.4$, and 0.75 , respectively. The IC was determined at 0.62 with the 3 items.

\subsection{Exploratory factor analysis among participants younger than $\mathbf{6}$ months}

Based on 46 measurements, Spearman's correlations were estimated and showed that cyanosis did not correlate with any of the items and had a zero variance; therefore, data could not be extracted for the EFA. Cyanosis was excluded from the analysis and showed a one-factor matrix with a $41 \%$ total variance that grouped respiratory rate, wheezing, and retractions, with factor loads of $0.5,0.6$, and 0.67 , respectively. The IC of these 3 items was 0.7 .

\subsection{Exploratory factor analysis among participants aged 6 months or older}

Based on 133 measurements, the matrix was analyzed and it was observed that cyanosis had a factor load inclined to another factor (Table 6). Once cyanosis was removed from the analysis, a new one-factor matrix was obtained that grouped respiratory rate, wheezing, and retractions with factor loads of $0.65,0.37$, and 0.75 , respectively, and an IC of 0.6.

TABLE 5. Factor matrix of the four score items

( $n=179$ measurements)

\begin{tabular}{lccc}
\hline & \multicolumn{3}{c}{ Factor } \\
& $\mathbf{1}$ & $\mathbf{2}$ \\
\hline Respiratory rate & 0.62 & \\
Wheezing & 0.38 & 0.50 \\
Cyanosis & & \\
Retractions & 0.82 & \\
\hline
\end{tabular}

Cronbach's alpha $=0.5$

TABLE 6. Participants aged 6 months or older: factor matrix of the four score items ( $n=133$ measurements)

\begin{tabular}{lcc}
\hline & \multicolumn{3}{c}{ Factor } \\
& $\mathbf{1}$ & $\mathbf{2}$ \\
\hline Respiratory rate & 0.62 & \\
Wheezing & 0.34 & 0.54 \\
Cyanosis & & \\
Retractions & 0.84 & \\
\hline
\end{tabular}

Cronbach's alpha $=0.52$ 


\section{DISCUSSION}

Some of the sociodemographic characteristics of the sample were that the mothers of most patients had completed secondary or tertiary education and that most patients did not live in over-crowding conditions; this had changed compared to the initiation of the ARI program in Chile, which was characterized by a low level of maternal education and over-crowding, therefore increasing the risk of death by pneumonia, a complication of obstructive bronchial diseases. ${ }^{11}$

In relation to the score, the biggest differences in proportions by observer were found in terms of cyanosis and retractions. This was probably due to the subjectivity entailed by both signs: they are observable but not measurable, whereas respiratory rate is measured over a specific period and wheezing is measured with an instrument (phonendoscope). ${ }^{20}$ The assessment of cyanosis and retractions depended on observation, an indirect, subjective method. ${ }^{21}$

In relation to the frequency and range of response, the patients on whom the test was applied had the same score for an item; therefore, the item "cyanosis" was probably not providing variability to the score ${ }^{14}$ because it is a late sign compared to the other items.

The EFA showed that one of the score items dissociated itself, which may be explained because cyanosis is a late sign of respiratory distress, which is observed once deoxygenated hemoglobin reaches $4-6 \mathrm{~g} / \mathrm{dl} ; \mathrm{a} \mathrm{SaO}_{2}$ of approximately $80-87 \%$ would result in clinically apparent cyanosis. ${ }^{22}$ This clinical sign may not provide information to the score's structure because once cyanosis was removed from analysis, only one construct was determined with increased consistency; however, such internal consistency provided values that ranged from objectionable to acceptable. It is necessary to consider that this estimation is below the assumption for continuous data and may have been underestimated. ${ }^{23,24}$

The matrices obtained for subgroup analysis showed the same behavior in relation to cyanosis, and the items "respiratory rate," "wheezing," and "retractions" were adjusted. This may be explained by what was mentioned above in relation to the fact that cyanosis is a late clinical sign, because most visits for obstructive bronchial disease were conducted early.

Compared to the factor matrix by age subgroup leaving out cyanosis, it was observed that all factor loads among patients younger than 6 months had values for the SBO construct that were above 0.6 . This may be explained because the younger the patient, the higher his/her airway resistance and instability, ${ }^{25}$ which become hyperreactive in case of infections, and this is consistent with the signs typical of the score.

It may be considered that the months for data collection -from August through November 2015- could have affected the typical rate of consultations in the winter season; however, over the past 5 years, ARIs have shown a bimodal behavior, with the highest peaks in consultations between June and August 2015 (the highest number occurred between August and September of this year). ${ }^{5}$

In relation to previous criterion validity, the study conducted by McCallum et al. ${ }^{12}$ observed a low diagnostic performance with this score. Coarasa et al. ${ }^{10}$ demonstrated a markedly lower sensitivity than the homologous score used in Argentina. In addition, Pavón et al. ${ }^{9}$ found that the item "cyanosis" of the modified Tal's score showed a lower level of correlation with peripheral oxygen saturation. Although these assessments do not seem related to the study's objective, they may be consistent with the score's behavior as a structure.

The criteria used in this design themselves assume only one approximation to validation of the SBO construct for this sample of boys and girls; therefore, it is necessary to complete it with a confirmatory factor analysis (CFA), which is a highly useful strategy in the setting of hypothesis testing and theory confirmation..$^{26,27}$ However, it could not be done mainly because of the absence of multicollinearity (there is no strong correlation between the model's explanatory outcome measures).

This study has certain limitations: 1) The size of the sample may be adequate based on theoretical recommendations but was made up preferably by male and female patients from the urban perimeter. Future studies should use representative samples of the general population, e.g. patients from rural areas or different geographic sectors, and with discrimination among different populations. 2) Most of the studied sample had a score equivalent to the mild bronchial obstruction category, and this did not allow to establish the correlation among outcome measures at the highest severity level.

The positive aspects of the study are that the EFA has been rigorous and although this exploratory approximation is not absolutely sufficient to modify the currently valid score, it 
gathers valuable, relevant information to consider the development of hypotheses and new studies as well as theoretical and empirical reflections about SBO measurement.

To make some recommendations: a) further studies are needed to replicate the results obtained with boys and girls from different sociocultural settings and to study the variability of the item "cyanosis;" b) a confirmatory factor analysis should be done together with invariance measurements to assess sensitivity to change or discriminated among different populations; c) further studies are required to establish the course of the SBO. The theory underlying the SBO construct may provide information in this line, with longitudinal studies that make an empirical analysis of the relationship between previous data and outcomes of the score's items.

\section{CONCLUSIONS}

For this sample, the studied phenomenon was not adequately represented by the score's items. Based on its items, the scale's structure does not fit adequately.

For the subgroup of participants younger than 6 months, the scale's structure does not fit appropriately. The structure's model shows acceptable internal consistency and would only involve respiratory rate, wheezing, and retractions. The item "cyanosis" appears as a dissociated item within the structure. Once the model is adjusted to only 3 items, the stability of Chronbach's alpha as a measure of internal consistency increases but at an objectionable value, which will undoubtedly vary once it is applied to a different sample.

\section{REFERENCES}

1. OMS. Medidas de control de infecciones en la atención sanitaria de pacientes con enfermedades respiratorias agudas en entornos comunitarios. Guía para el instructor. OMS; 2009. [Accessed on: July $5^{\text {th }}, 2017$ ]. Available at: http: / / apps.who.int/iris / bitstream/10665/70233/1/ WHO_HSE_GAR_BDP_2009.1_spa.pdf.

2. Chile. Ministerio de Salud. Consultas de morbilidad por enfermedades respiratorias en salas IRA, ERA y Mixta, por Región y Servicio de salud, SNSS 2014. Departamento de Estadística e Información de Salud. 2014. [Accessed on: July $\left.5^{\text {th }}, 2017\right]$. Available at: http://intradeis. minsal.cl / reportesrem / 2014 / REM23SECCIOND / REM23SECCIOND.aspx.

3. Chile. Ministerio de Salud. Guía Clínica Auge Infección Respiratoria Aguda Baja de Manejo ambulatorioen menores de 5 años. 2013. [Accessed on: July $4^{\text {th }}$, 2017]. Available at: http:/ / www.minsal.cl/portal/url/item/7220fdc4341244 a9e04001011f0113b9.pdf.

4. Girardi GB, Astudillo PO, Zúñiga FH. El programa IRA en Chile: hitos e historia. Rev Chil Pediatr 2001;72(4):292-300.
5. Bekhof J, Reimink R, Brand PL. Systematic review: Insufficient validation of clinical scores for the assessment of acute dysponea in wheezing children. Pediatr Respir Rev 2014;15(1):98-112.

6. Luarte-Martínez S, Rodríguez-Núñez I, Astudillo P, et al. Propiedades psicométricas de las escalas de gravedad de obstrucción bronquial en pediatría. Revisión sistemática y metaanálisis. Arch Argent Pediatr 2017;115(3):241-8.

7. Bierman CW, Pierson WE. The Pharmacologic Management of Status Asthmaticus in Children. Pedriatrics 1974:54;245-7.

8. Tal A, Bavilski C, Yohai D, et al. Dexamethasone and Salbutamol in the Treatment of Acute Wheezing in Infants. Pediatrics 1983;71(1):13-8.

9. Pavón D, Castro-Rodríguez JA, Rubilar L, et al. Relation between pulse oximetry and clinical score in children with acute wheezing less than 24 months of age. Pediatr Pulmonol 1999;27(6):423-7.

10. Coarasa A, Giugno H, Cutri A, et al. Validación de una herramienta de predicción clínica simple para la evaluación delagravedad en niños con síndromebronquial obstructivo. Arch Argent Pediatr 2010;108(2):116-23.

11. Puebla Molina S, Bustos L, Valenzuela M, et al. La escala de Tal como test diagnóstico y el diagnóstico clínico como gold standard en el síndrome bronquial obstructivo del lactante. Rev Pediatr Aten Primaria 2008;10(37):45-53.

12. McCallum GB, Morris PS, Wilson CC, et al. Severity scoring systems: are they internally valid, reliable and predictive of oxygen use in children with acute bronchiolitis? Pediatr Pulmonol 2013;48(8):797-803.

13. Alarcón A, Muñoz S. Medición en Salud: Algunas consideraciones metodológicas. Rev Med Chile 2008;136(1):125-30.

14. Sánchez R, Echeverry J. Validación de escalas de medición en salud. Rev Salud Pública 2004;6(3):302-18.

15. Abell N, Springer DW, Kamata A. Developing and validating rapid assessment instruments. Oxford: Oxford University Press; 2009.

16. McDowell I, Newell C. The Theoretical and technical Foundations of Health Measurement. In: Measuring Health: a guide to rating scales and questionnaires. 2 nd ed. New York: Oxford University Press; 1996.Págs.10-46.

17. Gerbin DW, Hamilton JG. Viability of Exploratory Factor Analysis as a Precursor to Confirmatory Factor Analysis. Struct Equ Modeling 1996;3(1):2-72.

18. Streiner DL, Norman GR. Health measurement scales: A practical guide to their development and use. 4th ed. Oxford, UK: Oxford University Press; 2008.

19. George D, Mallery M. SPSS for Windows Step by Step: A Simple Guide and Reference 21.0.13th ed. Boston: Allyn \& Bacon/Prentice Hall; 2013.

20. Sánchez I. Aplicaciones clínicas del estudio objetivo de los ruidos respiratorio en pediatría. Rev Chil Pediatr 2003;74(3):259-68.

21. Cruz M. Aparato respiratorio. In: Nuevo Tratado de Pediatría. 2.da ed. Barcelona: Océano-Ergón; 2011. Págs.1420-32.

22. Steinhorn RH. Evaluation and management of the cyanotic neonate. Clin Pediatr Emerg Med 2008;9(3):169-75.

23. George D, Mallery P. SPSS for Windows step by step: A simple guide and reference. 11.0 update. 4 th ed. Boston: Allyn \& Bacon; 2003.

24. Oliden PE, Zumbo BD. Coeficientes de fiabilidad para escalas de respuesta categórica ordenada. Psicothema 2008;20(4):896-901.

25. Rodríguez I, Báez C, Contreras T, et al. Kinesioterapia respiratoria en la bronquiolitis aguda: estrategia terapéutica, bases fisiológicas e impacto clínico. Neumol Pediatr 2013;8(3):111-5. 
e376 / Arch Argent Pediatr 2017;115(6):e370-e376 / Original article

26. Batista Foguet JM, Coenders G, Alonso J. Análisis factorial confirmatorio. Su utilidad en la validación de cuestionarios relacionados con la salud. Med Clín (Barc) 2004;122(Supl 1):21-7.
27. Batista Foguet JM, Coenders Gallart G. Modelos de ecuaciones estructurales: modelos para el análisis de relaciones causales. Cuadernos de estadística. 2.da ed. Madrid: La Muralla; 2000. 